\title{
Spinal Cord Stimulation for Managing Angina from Coronary Artery Disease
}

\author{
Billy Huh \\ Department of Anesthesiology, Duke University Medical Center, \\ USA
}

\section{Introduction}

Despite the recent advances in managing angina pectoris, many patients with coronary artery disease suffer from intractable pain. For those patients who have already failed optimal medical and surgical therapy, very few, if any, therapeutic options are available. However, spinal cord stimulation (SCS) may play a unique role in managing such refractory anginal pain.

The analgesic effect of SCS has been known since 1967 when Norman Shealy was able to show electrical stimulation of the dorsal column of spinal cord suppressed the response to noxious stimulation in animal study and abolished pain in a patient with terminal cancer (Shealy et.al. 1967). The rationale for this technique was based on the "gate theory" of pain proposed by Melzack and Wall (Melzack \&Wall 1965). The SCS has been used mostly in patients suffering chronic low back pain but has also been used successfully in a variety of other conditions including radiculopathy, complex regional pain syndrome, post-herpetic neuralgia, multiple sclerosis, and other types of neuropathic pain. Moreover, several studies were able to demonstrate the pain relieving effect of SCS in peripheral vascular disease, associated with an increase in local blood flow as well as angina pectoris (Augustinsson et.al., 1985; Cook et.al., 1976; Jacobs et.al., 1990; Murphy et.al., 1987).

The use of electrical stimulation to manage angina was initially reported by Mannheimer et.al. (1982). The study showed that patients with severe angina pectoris treated with transcutaneous electrical nerve stimulation (TENS) reported decreased frequency and severity of anginal attacks, improved exercise tolerance, and a reduction in ST segment depression in electrocardiogram. But TENS unit is not suitable for long term therapy due to skin irritation and the stimulation equipment often restricted physical activity.

Murphy et.al. (1987) placed SCS in the dorsal column in 10 patients with intractable angina pectoris. All patients were suffering with severe intractable angina pectoris, unresponsive to maximal medical therapy and not suitable for coronary artery bypass surgery, and all had angina at rest or on minimal exertion. Three patients had suffered myocardial infarction previously, and five patients had previously undergone coronary artery bypass surgery. The patients were typically on $\beta$-blocker, calcium channel blocker, diuretics, and topical or sublingual nitroglycerin as needed. 
All patients reported excellent results following the implantation with a significant decrease in both severity and frequency of angina attacks. All patients were able to reduce sublingual nitroglycerin requirement. One patient has returned to work. Three patients who experienced recurrence of angina, one had previously documented myocardial infarction (MI) and coronary artery bypass graft (CABG). He had two episodes of angina pectoris after almost 3 years after the implant.

In another patient angina recurred for the first time 2 years after SCS. A third patient complained of a return of angina in a new location, not covered by the area of dorsal column stimulation. Insertion of an additional electrode succeeded in relieving the new angina. Three patients have died of complications related to their ischemic heart disease, 5 to 32 months after the SCS implant. Another patient died of cardiogenic shock from MI nearly 7 months after the implantation.

Mannheimer et.al. (1988 \& 1998) showed that SCS increased patients' tolerance to elevated heart rate under the controlled pacing. At the heart rate comparable to that producing angina, myocardial lactate production diminished, ST segment depression decreased, time to ST depression increased, and time to recovery from ST depression decreased respectively. SCS also reduced coronary sinus blood flow and myocardial oxygen consumption. Myocardial lactate level increased and the magnitude and duration of ST segment depression increased to the same values as during control pacing, indicating that myocardial ischemia during treatment with SCS can give rise to anginal pain. Thus spinal cord stimulation has an anti-anginal and anti-ischemic effect in severe coronary artery disease. These effects seem to be secondary to a decrease in myocardial oxygen consumption, and SCS does not mask the patient of a warning signal.

Similarly, Sanderson et. al. (1992) studied effectiveness of SCS in 14 patients with severe intractable angina unresponsive to standard therapies including bypass grafting. After implantation of SCS units, the patients were assessed by a symptom questionnaire, treadmill exercise, and atrial pacing. There was a significant improvement of angina, and nitroglycerine usage decreased markedly. SCS increased exercise duration from a mean of 414 to 478 seconds, and total ST segment depression was decreased both at maximum exercise (7.1 vs. $5.6 \mathrm{~mm})$ and at $90 \%$ of the maximum control heart rate (3.5 vs. $2.6 \mathrm{~mm})$. During the right atrial pacing, the maximum heart rate was reached before onset of angina (143 vs. 150 per min), and total ST segment depression was less at all heart rates. Benefit has persisted in some patients for over 2 years

A retrospective analysis of patients from the Italian Multicenter Registry (Romano et.al. 2000) showed that SCS is an effective therapy in patients with refractory angina pectoris, especially for those who cannot undergo revascularization procedure. One hundred and thirty patients (83 males, 47 females, mean age 74.8) were given SCS implantation for refractory angina and followed for $31.4+/-25.9$ months. The follow-up data of 116 patients $(89.2 \%)$ showed that SCS resulted in significant decrease in New York Heart Association (NYHA) functional class from 2.5 to 1.5 ( $\mathrm{p}<0.01)$. During the follow-up 41 patients $(35.3 \%)$ died, and $14.2 \%$ developed a new acute MI. The annual total mortality rate was $6.5 \%$, whereas the cardiac mortality rate was $5 \%$. Compared to the survivors, patients who died showed a higher incidence of left ventricular dysfunction, previous MI and bypass surgery at implantation. 


\section{Outcome studies}

A first long term outcome study performed by Sanderson et.al. (1994) confirmed that SCS is an effective and safe form of alternative therapy for the patient whose angina is unresponsive to conventional therapies. The results were from follow-up study over a period of 62 months on 23 patients who had SCS implanted for intractable angina unresponsive to standard therapy. Symptomatic improvement was good and persisted with a mean change of NYHA grade from 3.1 pre-operatively to $2.0(\mathrm{P}<0.01)$ immediately after operations. Nitrite consumption fell markedly. Mean treadmill exercise time increased from 407 to $499 \mathrm{sec}(\mathrm{P}<0.01)$. Forty-eight hour ST segment monitoring in those with SCS showed a reduction of frequency and duration of ischemic events. There were three deaths, none of which were sudden or unexplained. Two patients had a myocardial infarction, which was associated with typical pain and not masked by the treatment.

In a prospective, controlled study, Hautvast et.al. (1998) randomized patients with chronic intractable angina pectoris to 13 treatment and 12 control groups. Inclusion criteria included chronic intractable angina pectoris class III or IV based on the NYHA criteria, unresponsive to beta-blocking agents, calcium antagonists, and nitrates. Myocardial ischemia was documented by $\geq 0.1 \mathrm{mV}$ ST depression during a treadmill exercise test, and coronary artery disease was documented by angiogram. Moreover, patients were not suitable for percutaneous coronary angioplasty or coronary artery bypass grafting. Exclusion criteria were the inability to perform an exercise test, cardiac stress test, and the anatomically unsuitable for stimulator implantation. The efficacy of SCS was evaluated for 6-week followup of daily intermittent stimulation compared with baseline and with a control group. Compared with control, SCS group exercise duration and time to angina increased; anginal attacks and sublingual nitrate consumption and ischemic episodes on 48-hour electrocardiogram (ECG) decreased. ST-segment depression on the exercise ECG decreased at comparable workload. Anginal attacks and consumption of sublingual nitrates decreased, perceived quality of life increased, and pain decreased.

In a larger prospective study, Mannheimer et.al. (1998) randomized 104 patients into SCS and CABG groups (SCS, 53; CABG, 51). The patients were assessed with respect to symptoms, exercise capacity, ECG changes during exercise, heart rate-blood pressure product, mortality, and cardiovascular morbidity before and 6 months after the operation. Both groups had satisfactory symptom relief $(\mathrm{P}<.0001)$, and there was no difference between SCS and CABG group. The CABG group had an increase in exercise capacity $(P=.02)$, less ST-segment depression on maximum $(P=.005)$ and comparable $(P=.0009)$ workloads, and an increase in the heart rate-blood pressure product both at maximum $(P=.0003)$ and similar $(P=.03)$ workloads compared with the SCS group. Eight deaths occurred during the followup period, 7 in the CABG group and 1 in the SCS group. On an intention-to-treat basis, the mortality rate was lower in the SCS group $(P=.02)$. Cerebrovascular morbidity was also lower in the SCS group $(P=.03)$. They concluded that efficacy of CABG and SCS to be equivalent in terms of symptom relief in this group of patients and concluded that SCS may be a good alternative for patients with an increased risk of surgical complications.

\section{Mechanism}

The mechanism of SCS induced anti-nociceptive response is not well understood. Several theories have been proposed and elucidated based on the previous investigations on both animal model and patients treated with SCS. 


\subsection{Sympathetic blockade}

The perception of pain during myocardial infarction is thought to be mediated by sympathetic afferent nerve fibers (Bonica et.al., 1990). Therefore, high thoracic epidural analgesia with local anesthetic can block cardiac afferent sympathetic fibers resulting in improved analgesia during myocardial infarction (Blomberg et. al., 1989). Mannheimer et. al. (1982; 1985) suggested that improved pain relief results in decreased sympathetic activity leading to improved blood flow.

In animal study, stimulation of spinal cord at weak to moderate intensity ( $50 \mathrm{~Hz} ; 0.2 \mathrm{msec}$; amplitude $2 / 3$ of evoking muscle contraction) improved ischemic conditions by suppressing sympathetic activity to the effector organ (Linderoth et.al., 1991a). In peripheral ischemic model, sympathectomy prior to SCS implant abolished benefits (Linderoth et.al. 1991b), and blockade of sympathetic preganglionic with hexamethnium or guanethidine totally abolished vasodilator effects of SCS (Linderoth et.al. 1991b, 1994a). Moreover, selective pharmacological blockade of autonomic transmission with an a-1 antagonist prazosine also prevented increase in blood flow with SCS.

However at higher intensity stimulation (90\% of motor threshold) Croom (1996a, 1996b) showed that SCS produced increased microvascular flow independent of hexamethomium or phentolamine, a a-1 adrenergic receptor antagonist (Croom et.al., 1997). Under the similar stimulation intensity, Foreman et.al. (1998) showed that SCS attenuated intrinsic cardiac neuronal activity, and the markedly decreased activity of neurons during local occlusion of coronary blood flow to the left ventricle. In another animal study, Olgin et.al. (2002) demonstrated that thoracic SCS slowed the sinus rate and prolonged atrioventricular (AV) nodal conduction time. This effect was not eliminated by bilateral sympathectomy, while bilateral vagal transection completely eliminated effect. In addition, thoracic SCS did not change nitric oxide (NO) level at the coronary sinus. Hence, they attributed decreased sinus rate and prolonged AV conduction to activation of parasympathetic system by SCS mediated via the vagus nerve.

Similarly, anti-anginal effect can be also achieved by SCS at higher intensity in human. Murphy et.al. (1987) first demonstrated a successful treatment of otherwise intractable angina pectoris at the range of amplitude: 3-7 volts, frequency: $80-100 \mathrm{~Hz}$, and pulse width: 250-500/sec. However, Sanderson et.al. (1995) used TENS in healthy volunteers and found weak association between TENS and an anti-sympathetic effect. Norsell et.al. (1997) have evaluated effect of SCS on myocardial and sympathetic tone in angina patients with SCS using norepinephrine (noradrenaline) spillover techniques. Their result showed very little effect of SCS in reducing cardiac sympathetic activity. Although overall sympathetic activity was decreased, they postulated this to reduced oxygen demand. In addition, Robertson et.al. (1983) studied plasma catecholamine levels in 10 patients with frequent spontaneous episodes of coronary artery spasm to evaluate the role of the sympathetic nervous system. Patients were evaluated for peripheral venous norepinephrine in supine and upright postures, urinary excretion of catecholamines, and functional testing of the sympathetic nervous system. Results showed that there were no changes in arterial and coronary sinus levels of norepinephrine and epinephrine drawn early in ischemia compared to the control. Plasma epinephrine levels, higher in arterial than coronary sinus samples, rose significantly only late in ischemia, hence generalized sympathetic nervous system activation is unlikely 
to be the sole cause of angina. Hence association between SCS induced relief of angina and anti-sympathetic effect is not robust.

\subsection{Blood flow}

Although SCS proved to have beneficial effects such as decreased anginal time, decreased duration and magnitude of ST segment depression during exercise compared with control values, but there were no significant changes in regional myocardial perfusion, as measured by positron emission tomography (PET) during exercise (De Landsherre, 1992). The previous studies have shown that TENS treatment failed to increase coronary sinus blood flow for patients with angina pectoris although anti-ischemic effect has been shown with improved myocardial lactate metabolism.(Cohen et.al., 1966; Emanuelssonm 1987; Mannheimer, 1989). Thus, literature studies do not support the hypothesis that the antiischemic effect of SCS is due to increase in coronary artery blood flow.

\subsection{Oxygen demand and supply balance}

The coronary venous oxygen tension is relatively constant during changes in myocardial oxygen consumption, and number of literature studies hinted that the coronary blood flow depends largely on autoregulatory mechanisms (Mosher, 1964; Miller, 1979). The animal study by Knabb (1983) showed a linear correlation between myocardial oxygen consumption and coronary blood flow. Coronary physiology study by Feigl (1983) showed that $\beta$-blockade gives rise to a reduction in both oxygen consumption and blood flow but did not affect the relation between these variables. It is possible that myocardial hypoxia leads to an increased concentration of adenosine, which produces arteriolar vasodilatation and an increase in blood flow, thus compensating for the decrease in myocardial oxygen tension. If SCS results in decrease in myocardial oxygen consumption, there will also be reduction in coronary blood flow.

\subsection{Direct pain inhibition}

Based on the original "gate theory" proposed by Melzack \&Wall (1965), there is also reason to believe that spinal cord stimulation has a direct pain inhibiting effect on angina. The animal study by Chandler et. al. (1993) found that spinal cord stimulation attenuated anginal pain by reducing the activity of the spinal thalamic tract neurons which transmit nociceptive somatic and cardiac impulses. Two other studies (Kroger, 1989; Blomberg, 1989) suggested that treatment which has a direct pain inhibiting effect also decreases the activity in the cardiac sympathetic nerves, hence decreases the myocardial oxygen requirement. Nevertheless, direct pain inhibiting effect theory seems valid but not the singular interpretation of the analgesic effect of SCS.

\subsection{Endogenous opioids}

In animal study, Oliveras et.al (1977) showed that the analgesic effects obtained in the cat by central inferior raphe nucleus stimulation are greatly reduced by the administration of a specific opiate antagonist, naloxone. Moreover, Tonelli et.al. (1988) showed 50\% increase in cerebrospinal $\beta$-endorphin and $\beta$-lipotropin levels for patients receiving good pain relief from SCS. These studies suggested link between SCS and endogenous opioid release, and 
implicated the $\beta$-endorphin response to SCS could have clinical value in predicting the success of treatment. On the contrary, Myerson et.al. (1977) showed that the pain relief produced by SCS is not reversed by naloxone.

The release of endogenous opioid via SCS may depend on stimulation frequency. Han et.al, (1991) studied two groups of patients receiving low-frequency $(2 \mathrm{~Hz})$ and high-frequency $(100 \mathrm{~Hz})$ transcutaneous nerve stimulation (TENS). The cerebrospinal fluid (CSF) sample obtained before and after stimulation showed that low frequency stimulation resulted in a significant increase $(367 \%, \mathrm{P}<0.05)$ of met-enkephalin but not dynorphin $\mathrm{A}$, whereas highfrequency $(100 \mathrm{~Hz})$ produced a $49 \%$ increase in dynorphin $\mathrm{A}(\mathrm{P}<0.01)$ but not metenkephalin. This is consistent with findings observed by Fei et.al. (1987) in animal experiments where low-frequency stimulation releases Met-enkephalin and high-frequency stimulation dynorphin A. The analgesia induced by low-frequency stimulation was readily reversed by naloxone and, therefore, probably mediated via mu-receptors; whereas analgesia induced by high-frequency stimulation required much higher doses of naloxone for reversal but was easily reversed by a kappa-receptor antagonist, indicating that the effects were mediated via kappa-receptors (Han et.al., 1986). Since dynorphins are preferred ligands for kappa-receptors, these studies strongly suggested that the opioid mechanism stimulated by high-frequency stimulation may be dynorphinergic.

\subsection{Amino acids and peptides}

The previous studies have shown that SCS can induce release of inhibitory amino acids such as substance $\mathrm{P}(\mathrm{SP})$, serotonin (5HT), $\gamma$-amino butyric acid (GABA), and glycine in the cerebral spinal fluid (CSF) (Linderoth et.al.1992, 1994b; Myerson et.al., 1985; Duggan \& Foong 1985; Simpson et.al., 1993). The antinociceptive properties of these substances are well documented depending on the location of administration in the central nerve system (CNS). Stiller et.al.(1996) showed that dysfunction of the spinal GABA system caused by the nerve damage in rats displayed tactile allodynia with significantly lower GABA in the dorsal horn compared to the control; while those responded to SCS showed dramatic increase in GABA and normalized withdrawal threshold. Moreover, the beneficial effect of SCS on allodynia could be reversed by the intrathecal injection of GABA-B antagonist; while the animals which failed to normalize tactile threshold due to the nerve lesion, intrathecal injection of GABA agonist (e.g., baclofen) increased threshold (Cui et.al., 1996).

The benefit of SCS may not be limited to the increased release of inhibitory neurotransmitters. Kangra et.al. (1991) and Hao (1993) showed that SCS can also decrease release of excitatory amino acids such as glutamate and aspartate in the dorsal horn; hence further modulating pain transmission. Cui et.al. (1997 \& 1998) showed that SCS can also activate release of adenosine, and simultaneous activation of GABA-B and adenosine A-1 receptors may exert synergistic action. The beneficial effect of SCS is completely abolished when both of these receptors are blocked at the same time. They have also observed that injection of GABA-B and adenosine simultaneously can potentiate the effect of SCS on animals, however human trial data is equivocal.

\subsection{Redistribution of blood flow}

Hautvast et. al. (1996) has shown that spinal cord stimulation at T1 induces the redistribution of myocardial blood flow, resulting in a decrease in angina pectoris attacks. 
The study demonstrated that spinal cord stimulation modulates regional cerebral blood flow (rCBF) in brain areas known to be involved in cardiovascular control and in areas associated with nociception. They postulated that the anti-anginal effect of SCS may therefore be the result of centrally mediated analgesic effects.

Mobilia et.al. (1998) studied 15 patients who already had SCS implanted for refractory angina pectoris. Eight patients had a previous MI and four patients had undergone a revascularization procedure. All patient underwent two positron emission tomographies (PET) with nitrogen-13-ammonia as the perfusion tracer. The first one was performed with the stimulator switched off for at least 20 hours, and the second one with the stimulator switched on for at least 4 hours. The quantitative evaluation of regional mean blood flow (MBF) showed an increase in regional myocardial perfusion with the stimulator was observed in $47(62 \%)$ out of 75 regions studied. Hence they concluded that the beneficial effects of SCS in refractory angina may be associated with an increase in mean MBF and to a redistribution of MBF between the regions with low or normal basal flow and the regions with high basal flow.

Murray et.al, (2000) has elegantly explained redistribution model of SCS on myocardial blood flow citing findings by Crea et.al. (1989) and Gaspardone et.al. (1993). The similarities between SCS and theophylline in angina treatment are such that both seem to improve exercise capacity, and anti-ischemic action does not appear to be mediated by systemic hemodynamic effects or by stenosis dilation. Therefore, the improvement of myocardial ischemia from SCS is probably due to redistribution of coronary blood flow toward the underperfused areas of myocardium.

At present the exact mechanism of action of neurostimulation is not known. All of the above mechanisms have been sought, and it is possible that more than one of them is responsible for the results of neurostimulation.

\section{Surgical technique and stimulation equipment}

The SCS lead is typically implanted in the operating room using sterile technique. Under the fluoroscopy guided technique, upper thoracic (T4 toT6 interspace) interspace is entered using Touhy needle to access epidural space. Usually single SCS lead is advanced up to C7 to T2 level. The procedure is performed under local anesthesia to allow the patient to communicate with the physician during the intraoperative testing. The electrode position is adjusted during the intraoperative testing such that the patient feels a paresthesia in the region of anginal pain. The ideal position is when the stimulation produces a paresthesia in the precordial area and spreading into the left arms as the current intensity is increased.

In order to enter epidural space at $\mathrm{T} 4$ to $\mathrm{T} 5$ interspace, skin entry point of Touhy needles is marked approximately 1 to 2 vertebral levels inferiorly. A 5 to $7 \mathrm{~cm}$ vertical skin incision is made from the needle entry point approximately one finger breadth lateral to the midline. The subcutaneous tissues are then cut down deep using bovie until dorsal column fascia is visualized. Then at the top of the incision, a Touhy needle is advanced toward epidural space 1 to $1 \frac{1}{2}$ levels above the entry site using paramedian approach at no greater than 45 degree approach using loss of resistance technique. The electrode tip is typically placed a few millimeters to the left of midline at the level of C7 to T2 (Figure 1) under the fluoroscopy guidance. Following the successful intraoperative testing, the electrode is sutured to the fascia using anchoring device. The pulse generator is typically placed in a subcutaneous pocket below the left costal arch or gluteal region. The lead is then tunnelled subcutaneously from the 
anchor site to the generator site. The pulse generator is then interrogated to ensure good lead connection. Antibiotic prophylaxis is required for implantable devices. Prophylactic antibiotics must be administered to the patient within 1 hour prior to surgical incision. Studies show that a single preoperative dose of antibiotic is as effective as a 5-day course of postoperative therapy assuming an uncomplicated procedure. Duration of prophylaxis beyond 24 hours or use of post operative antibiotics are generally not recommended (The Medical Letter 2004; Fabian et.al., 1992; Bozorgzadeh et.al., 1999; Luchette et.al., 2006).

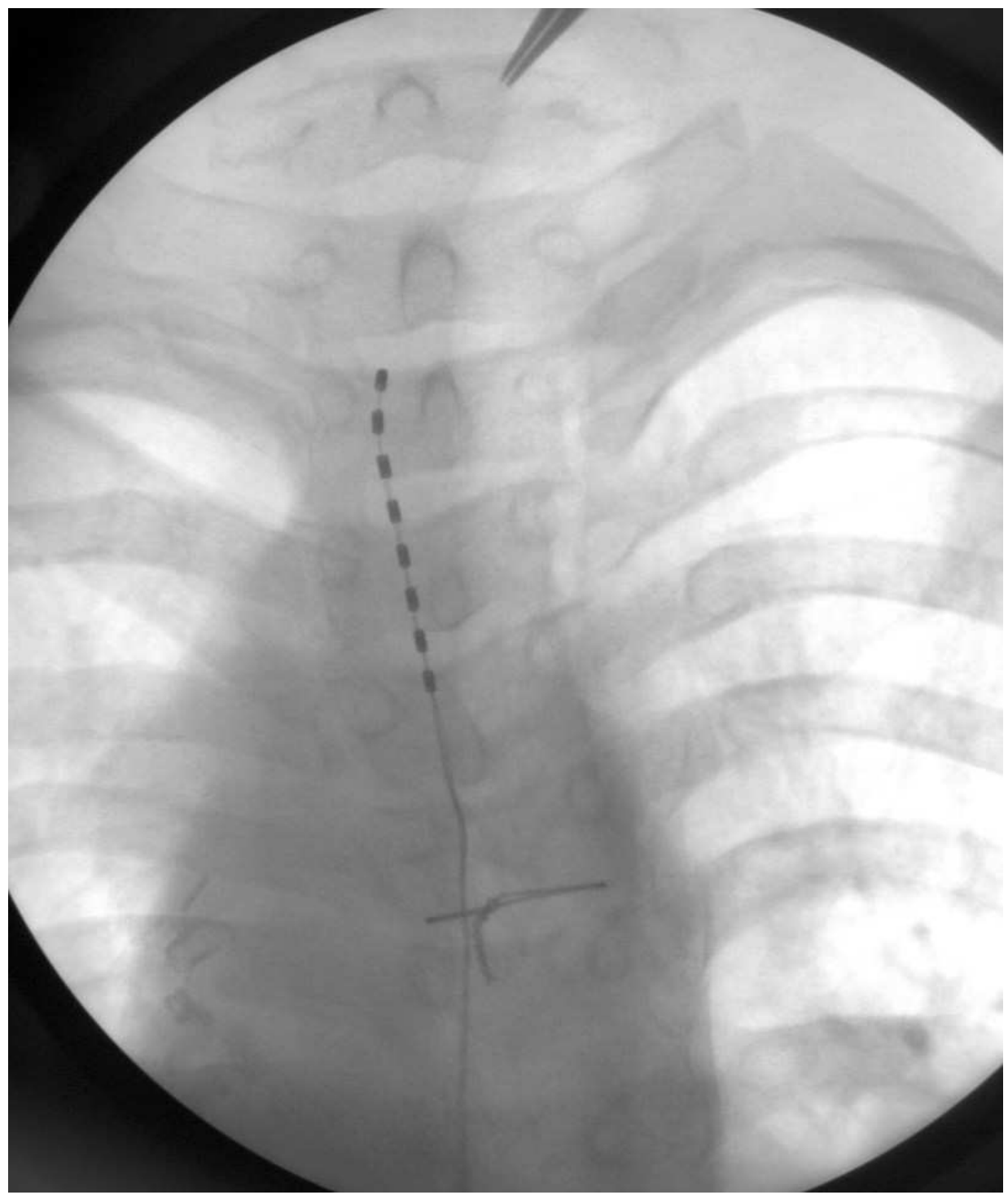

Fig. 1. SCS lead placement at upper thoracic spine. 


\section{Indications and patient selection}

The patients with refractory angina pectoris referred to our pain clinic by cardiologist usually has exhausted optimal therapeutic modalities including pharmacotherapy ( $\beta$ blocker, calcium channel antagonist, vasodilator), surgical (e.g., coronary artery bypass graft (CABG), percutaneous transluminal coronary angioplasty (PTCA), stent placement, etc), and often maintained on anticoagulant and potent opioid analgesics which referring physicians are uncomfortable sustaining. Therefore, these patients are considered inoperable and untreatable. The inclusion and exclusion criteria are well described in Table 1 (De Vries et.al. 2007). The algorithmic approach to angina pectoris depicted in Figure 2 (Kleef et.al. 2011) shows that SCS has its niche as the last resort treatment for managing refractory angina.

In the United States, use of SCS for angina is still considered "off label." Hence there are considerable obstacles to obtaining health insurance preauthorization. The prior treatment history is rigorously scrutinized, and often requires peer to peer review between the treating physician and physicians representing insurance company. Such process leads to further delay in providing treatment in a timely manner, and patients tend to become sub-optimal for the procedure. Therefore, the use of SCS for angina is not as common in the United States compared to Europe.

\section{Inclusion criteria}

1. Severe chest pain (NYHA classes III-IV or VAS score $>7$ )

2. Optimal tolerated pharmacological therapy

3. Significant coronary artery disease (i.e. $>1$ stenosis of $75 \%$ )

4. Not eligible for Percutaneous Transluminal Intervention or Coronary Artery Bypass Surgery

5. No prognostic benefit from surgical revascularization (according to guidelines)

6. Patient considered intellectually capable to manage the SCS device

7. No acute coronary syndrome during last 3 months

\section{Exclusion criteria}

1. Myocardial infarction within the last 3 months

2. Uncontrolled disease such as hypertension or diabetes mellitus

3. Personality disorders or psychological instability

4. Pregnancy

5. Implantable cardioverter defibrillator (ICD) and pacemaker dependency

6. (Local) infections

7. Insurmountable spinal anatomy

8. Contraindication to withheld anti-platelet agents or coumadins

9. Addictive behavior

*De Vries et.al. (2007). With permission

Table 1. Inclusion and exclusion criteria SCS for ischemic heart disease (IHD)* 


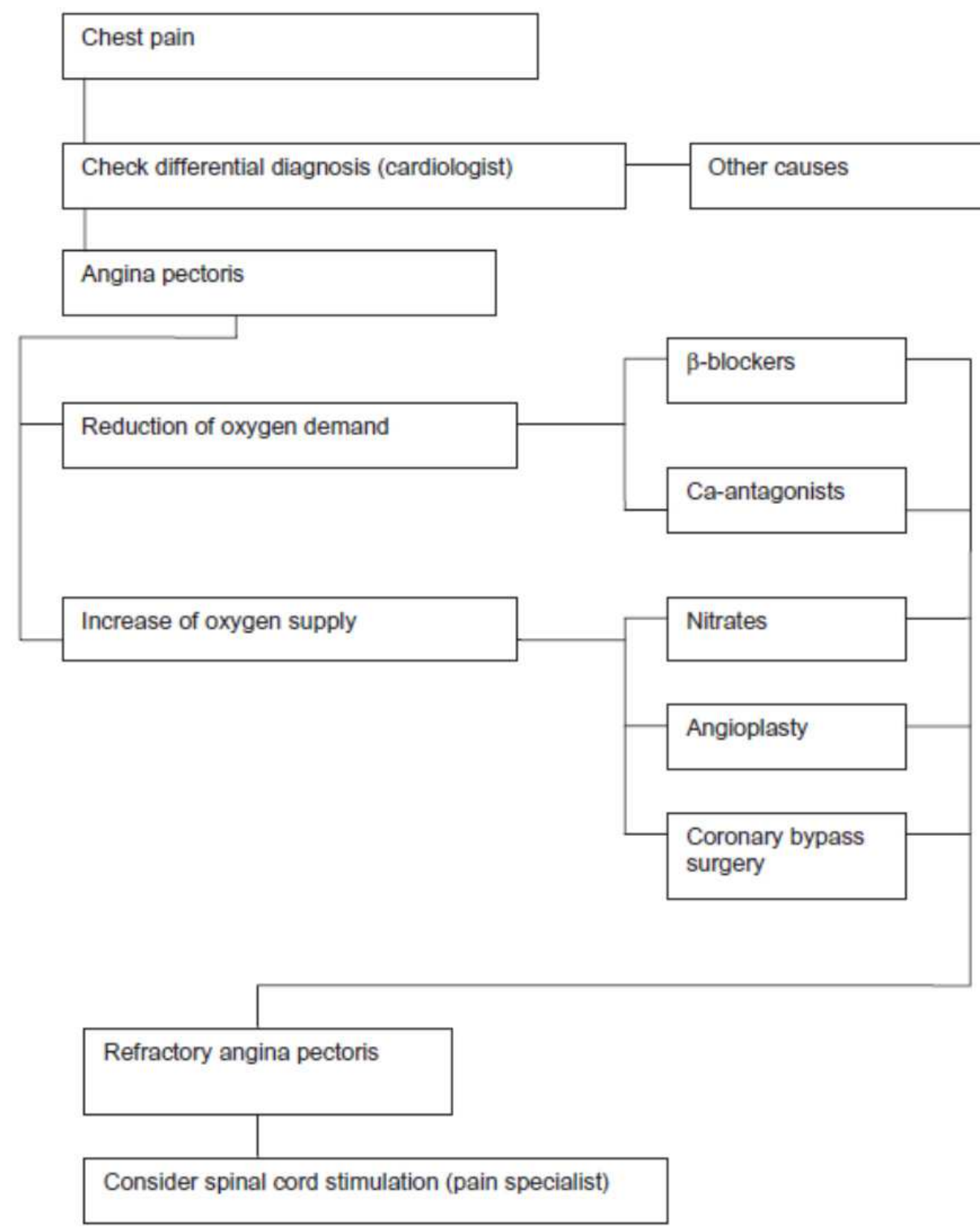

Fig. 2. Algorithm for the treatment of refractory angina pectoris (Kleef et.al. 2011). With permission.

\section{Cost effectiveness}

The cost-effectiveness of spinal cord stimulation in patients with intractable angina has been assessed by Merry et.al. (2001). The cost of healthcare utilization by patients suffering from intractable angina, unsuitable for coronary revascularization, before and after treatment 
with spinal cord stimulation on eight patients. Information on consumption of specified medical resources for the twelve months preceding implantation, the implantation period, and the twelve months following implantation was collected. Where available, data were also collected for the eighteen months preceding and following treatment.

The six patients with successful stimulation spent fewer days in hospital $(p=0.028)$ and consumed fewer resources $(p=0.046)$ following implantation than in the period before implantation. The two patients for whom spinal cord stimulation was unsuccessful spent more days in hospital and consumed more resources in the twelve months following, than in the twelve months preceding attempted implantation. Extrapolation of data for all eight patients suggests that, on average, the cost of implanting a spinal cord stimulator will be recovered in approximately fifteen months.

The retrospective study by Rasmussen et.al. (2004) assessed economic significances of SCS treatment on 18 consecutive patients. Before implantation of the SCS system, the patients were in a TENS treatment for 2-11 months. At the time of implant all patients were in NYHA functional group III/IV. The study is based on cost data from the year prior to start of TENS treatment compared with the year after implantation of the SCS system. They found that SCS is effective in reducing hospital and non-hospital related expenses.

Several additional studies have also showed cost effectiveness following the SCS implantation. The 2-year follow-up of the 104 patients participating in the Electrical Stimulation versus Coronary Artery Bypass Surgery in Severe Angina Pectoris (ESBY) study by Andréll et.al. (2003) found that SCS is less expensive than coronary artery bypass grafting in treating angina pectoris. The SCS group had fewer hospitalization days related to the primary procedure and to cardiac events. A systematic review by Taylor et. al. (2004) demonstrated that the initial costs of the SCS are offset by a reduction in post-implant healthcare demand and costs.

Murray et al. (1999) showed that the average time the patients were in the hospital after revascularization was 8.3 days per year versus 2.5 days per year after SCS. The authors confirmed that SCS was effective in preventing hospital admissions in patients with refractory angina.

\section{Stimulation parameter}

Stimulation parameters are usually different for each patient as stimulation is individualized to produce optimal relief in each patient. Our own experience and published parameter range for angina vary widely. For the purpose of reference, the range of stimulation parameters published is: pulse amplitude 1-10 volt, frequency $80-100 \mathrm{~Hz}$, pulse width 150 to $500 \mu \mathrm{sec}$ (Murphy et.al. 1987; Hautvast et. al. 1997; Gersbach et.al. 2001).

\section{Complications}

The major complications of SCS implant are rare, and most complications are minor and limited to superficial infection, lead migrations, battery failure and electrode fractures (De jongste et.al. $1994 \& 2000$ ). The overall complication rate in the literature is up to $12 \%$ (Borjesson et.al. 2008), but the complication rate is highly dependent on implanter's experience, technique, and patient factor. It seems logical to expect higher complication rate from the inexperienced implanter. The earlier studies showed higher incidence of lead migration (De Jongste and 
Staal, 1993; Jessurun et.al., 1997). But our own experience over last 10 years show dramatic decrease in lead migration in part attributed to improved lead anchor technologies.

Discomfort at implantable electrical pulse generator (IPG) sites is not uncommon and often results in persistent pain in patients with spinal cord stimulator. The IPG is most frequently implanted in the gluteal region to take advantage of the natural cushion provided by the abundance of adipose tissue in the buttock area. However, IPG sites are subject to unrelenting pressure and trauma of daily activities such as sitting, lying down, and bending leading to cutaneous hyperalgesia. Often, patients require additional analgesics or revision of the IPG pocket to control pain. A retrospective review of 20 patients at our institution (Huh and Kuo, 2011) who underwent revision due to painful IPG site (9 relocation versus 11 deep implantation at the same site) showed that decrease in pain score was significant within each group $(p<0.001)$, but no significant difference in pain was found between the two techniques $(p=0.5779)$. However, we recommend deep re-implantation of the IPG at the original site over the relocation due to the simplicity of the procedure. Re-implantation does not require creating a new pocket, and it is not limited by the length of the electrode.

\section{Conclusion}

Spinal cord stimulation (SCS) is an alternative therapy for patients with intractable angina who has not responded to standard therapies. Studies shows that SCS provide relief from the angina pain, decrease use of analgesia and nitrates, decrease incidence of ischemic attacks, improve heart function and quality of life

Although there is abundant evidence from Europe to show the benefits of SCS for refractory angina pectoris, the use of SCS in the United States is still considered experimental. Hence at large academic institutions, CABG is still the most commonly performed procedure for severe CAD. Health insurance coverage for SCS is challenging for angina pectoris. The scope of the disease process is enormous, and future direction begs to invest in a large multicenter prospective study to obtain Food and Drug Administration approval to benefit patients

\section{References}

Andréll P, Ekre O, Eliasson T, Blomstrand C, Börjesson M, Nilsson M, Mannheimer C. CostEffectiveness of Spinal Cord Stimulation versus Coronary Artery Bypass Grafting in Patients with Severe Angina Pectoris - Long-Term Results from the ESBY Study. Cardiology 2003;99:20-24.

Augustinsson LE, Carlsson CA, Holm J, Jivegird L. Epidural electrical stimulation in severe limb ischemia. Ann Surg 1985;202:104-10.

Blomberg S, Curelaru I, Emanuelsson H, Herlitz J, Ponten J, Rickten SE. Thoracic epidural anesthesia in patients with unstable angina pectoris. Eur Heart J 1989;10: 437-44.

Bonica JJ. The management of pain. Vol II. 2nd ed .Philadelphia: Lea and Febiger, 1990;1001-30.

Borjesson M, Andrell P, Lundberg D, Mannheimer C. Spinal cord stimulation in severe angina pectoris - A systemic review based on the Swedish Council on Technology assessment in health care report on long-standing pain. Pain 2008;140:501-508.

Bozorgzadeh A, Pizzi WF, Barie PS, et.al. The duration of antibiotic administration in penetrating abdominal trauma. Am J Surg 1999;177:125-31.

Chandler MJ, Brennan TJ, Garrison DW, Kim KS, Schwartz PJ, Forman RD. A mechanism of cardiac pain suppression by spinal cord stimulation: implications for patients with angina pectoris. Eur Heart J 1993;14:96-105. 
Cohen LS, Elliott WC, Klein MD, Gorlin R. Coronary heart disease. Clinical cinearteriographic and metabolic correlations. Am J Cardiol 1966;17: 153-68.

Cook AW, Oygar A, Baggenstos P, Pacheco S, Kleriga E. Vascular disease of extremities. Electrical stimulation of spinal cord and posterior roots. NY StateJMed 1976;76:366-8.

Crea F, Pupita G, Galassi A, et al. Effect of theophylline on myocardial ischaemia. Lancet 1989;i:683-6.

Croom JE. Mechansims for cutaneous vasodiltation due to electrical stimulation of the dorsal surface of the spinal cord. Thesis. University of Oklahom, Oklahoma City 1996a:173.

Croom JE, Barron KW, Chandler MJ, Foreman RD. Cutaneous blood flow increases in the rat hind paw during dorsal column stimulation. Brain Res 1996b:728:281-286.

Croom JE, Foreman RD, Chandler MJ, Barron KW. Cutaneous vasodilation during dorsal column stimulation is mediated by dorsal roots and CGRP. Am J Physiol 1997:272:H950-H957.

Cui J-G, Linderoth B, Meyerson BA. Effects of spinal cord stimulation on touch-evoked allodynia involve GABAergic mechanism. An experimental study in the mononeuropathic rat. Pain 1996;66:287-295.

Cui J-G, Sollevi A, Linderoth B, Meyerson BA. Adenosine receptor activation suppresses tactile hypersensitivity and potentiates effect of spinal cord in mononeuopathic rats. Neurosci Lett 1997;223:173-176.

Cui J-G, Meyerson BA, Sollevi A, Linderoth B. Effects of spinal cord stimulation on tactile hypersensitivity in mononeuropathic rats is potentiated by $\mathrm{GABA}_{\mathrm{B}}$ and adenosine receptor activation. Neurosci Lett 1998;247:183-186.

De Jongste MJ, Staal MJ. Preliminary results of a randomized study on the clinical efficacy of spinal cord stimulation for refractory angina pectoris. Acta Neurochir Suppl 1993;58:161-4.

DeJongste MJL, Nagelkerke D., Hooyschuur CM, Journke HL, Meyler WJ, Staal M J, de Jonge PJ, Lie KI. Stimulation characteristics, complications, and efficacy of spinal cord stimulation systems in patients with refractory angina. A prospective feasibility study. PACE 1994; 17:1751-1760.

DeJongste MJ. Spinal cord stimulation for ischemic heart disease. Neurol Res 2000;22:293-298.

De Landsherre C, Mannheimer C, Habets A, Guillame M, Bourgeois I, Augustinsson L-E, et al. Effect of spinal cord stimulation on regional myocardial perfusion assessed by positron emission tomography. Am J Cardiol, 1992 ;69:1143-9.

De Veries J, De Jongste MJL, Spincemaille G, Staal M. Spinal cord stimulation for ischemic heart disease and peripheral vascular disease. Advances and Technical Standards in Neurosurgery 2007; 32;64-84.

Duggan AW, Foong FW. Bicuculline and spinal inhibition produced by dorsal column stimulation in the cat. Pain 1985;22:249-250.

Emanuelsson H, Mannheimer C, Waagitein F, Wilhelmsson C. Catecholamine metabolism during pacing-induced angina pectoris and the effect of transcutaneouse elctrical nerve stimulation. Am Heart J 1987;114:1360-6.

Fabian TC, Croce MA, Payne LW, et.al. Duration of antibiotic therapy for penetrating abdominal trauma: a prospective trial. Surgery 1992;112:788-95.

Fei H, Xie GX, Han JS. Low and high frequency electroacupuncture stimulation release met 5enkaphalin and dynorphin A and B in rat spinal cord. Chin Sci Bull 1987;32:1496-1501. 
Feigl EO. Coronary physiology. PhysiolRev 1983;63:1-205.

Foreman RD, Ardell JL, Armour JA et.al. High thoracic spinal cord stimulation attenuates intrinsic cardiac neuronal actvity in the dog: Implication for treating refractory angina pectoris. Soc Neuroscit Abstr 1998;24(part I):394 (No. 154:19).

Gaspardone A, Crea F, Iamele M, et al. Bamiphylline improves exercise-induced myocardial ischaemia through a novel mechanism of action. Circulation 1993;88:502-8.

Gersbach PA, Hasdemi MG, Eeckhout, von Segesser LK. Spinal Cord Stimulation Treatment for Angina Pectoris: More Than a Placebo? Ann Thorac Surg 2001;72:S1100-4.

Han JS, Dingh XZ, Fan SG. The frequency as the cardinal determinant for electroacupuncture analgesia to be reversed by opioid antagonist. Acta physiol Sin 1986;38:475-482.

Han JS, Chen XH, Sun SL et.al. Effect of low and high-frequency TENS on Met-enkephalinArg-Phe and dynorphin. A immunoreactivity in human lumbar CSF. Pain 1991;47:295-298.

Hao J. Photochemically induced spinal ischemia: behavioral, electrophysiological and morphological studies with special emphasis on sensory function. Thesis, Karolinska Institute, Stockholm 1993.

Hautvast, R. W. M., Blanksma, P. K., DeJongste, M. J. L., Pruim, J., van der Wall, E. E., Vaalburg, W. and Lie, K. I. Effect of spinal cord stimulation on myocardial blood flow assessed by positron emission tomography in patients with refractory angina pectoris. Am. J. Cardiol., 1996; 77:462-467.

Hautvast RWM, Horst GJT, DeJong BM, DeJongste MJL, Blanksma PK, Paans AMJ, and Korf J. Relative Changes in Regional Cerebral Blood Flow During Spinal Cord Stimulation in Patients with Refractory Angina Pectoris, European Journal of Neuroscience, 1997; 9:1178-1183.

Hautvast RWM, DeJongste MJL, et.al. Spinal cord stimulation in chronic intractable angina pectoris: A randomized, controlled efficacy study. Am Heart J., 1998; 136:1114-20.

Huh BK, Kuo CP. Comparing the Efficacy of Two Revision Techniques for Reducing Pain at Spinal Cord Stimulator Implantable Pulse Generator Sites. American Society of Anesthesiologist Annual Meeting Abstract \#950. October 16, 2011.

Jacobs MJHM, Jorning PJG, Beckers RCY, Ubbink DT, van Kleef M, Slaaf DW, et al. Foot salvage and improvements of microvascular blood flow as a result of epidural spinal cord electrical stimulation. J Vase Surg 1990; 12: 354-60.

Jessurun GA, TenVaarwerk IA, DeJongste MJ, Tio RA, Staal MJ. Sequelae of spinal cord stimulation for refractory angina pectoris. Reliability and safety profile of longterm clinical application. Coronary Artery Dis 1997;8:33-8.

Kangra I, Jing M, Randic M. Actions of baclofen on rat dorsal horn neurons. Brain Res 1991;562:265-275.

Kleef MV, Staats P, Mekhail N, Huygen F, Chronic Refractory Angina Pectoris. Pain Practice. early on line publication, March 2011.

Knabb RM, Ely SW, Bacchus AN, Rubio R, Berne RM. Consistent parallel relationships among myocardial oxygen consumption, coronary blood flow, and pericardial infuate adenosine concentration with various interventions and $\beta$-blockade in the dog. Circ Res 1983; 53:33-41.

Kroger K, Schipke J, Thimer V, Heusch G. Poststenotic ischaemic myocardial dysfunction induced by peripheral nociceptive stimulation. Eur Heart J 1989;10:179-82.

Linderoth B, Fedorcsak I, Meyerson BA. Peripheral vasodilation after spinal cord stimulation: animal studies of putative effector mechanisms. Neurosurgery 1991a;28:187-195. 
Linderoth B, Gunasekera L, Meyerson B. Effects of sympathectomy on skin and muscle microcirculation during dorsal column stimulation: animal studies. Neurosurgery 1991b:29:874-879.

Linderoth B, Gazelius B, Franck J, Brodin E. Dorsal column stimulation induces release of serotonin and substance P in the cat dorsal horn. Neurosurgery 1992;31:289-297.

Linderoth B, Herregodts P, Meyerson B. Sympathetic mediation of peripheral vasodilatation induced by spinal cord stimulation: animal studies of the role of cholinergic and adrenergic receptor subtypes. Neurosurgery 1994a;35:711-719.

Linderoth B., Stiller CO, Gunasekera L, O'Connor WT, Ungerstedt U, Brodin E. Gammaaminobutyric acid is released in the dorsal horn by electrical spinal cord stimulation: an in vivo microdialysis study in the rat. Neurosurg 1994b;34:484-489.

Luchette FA, Borzotta AP, Croce MA, et.al. Practice management guidelines for prophylactic antibiotic use in penetrating abdominal trauma. Available online at: http://www.east.org. [Accessed 09 October 2006].

Mannheimer C, Carlsson CA, Ericson K, Vedin A, Wilhelmsson C. Transcutaneous electrical nerve stimulation in severe angina pectoris. Eur Heart J, 1982;3:297-302.

Mannheimer, C., Carlsson, C.A., Emanuelsson, H., Vedin. A., Waagstein, F. et al.. The effects of transcutaneous electrical nerve stimulation in patients with severe angina pectoris. Circulation, 71 (1985) 308-316.

Mannheimer C, Augustinsson L-E, Carlsson C-A, Manhem K, Wilhelmsson C. Epidural spinal electrical stimulation in severe angina pectoris. Br Heart J, 1988; 59:56-61.

Mannheimer C, Emanuelsson H, Waagstein F, Wilhelmsson C. Influence of naloxone on the effects of transcutaneous electrical nerve stimulation (TENS) in pacing-induced angina pectoris. Br Heart J. 1989;62:36-42.

Mannheimer C, Eliasson T, Augustinsson LE, et al. Electrical stimulation versus coronary artery bypass surgery in severe angina pectoris: the ESBY study. Circulation 1998;97:1157-1163.

Melzack R, Wall P, Pain mechanisms: A new theory. Science 1965; 150:971-9.

Merry AF, Smith WM, Anderson DJ, Emmens DJ, Choong CK, Cost-effectiveness of spinal cord stimulation in patients with intractable angina. N Z Med J 2001 Apr 27;114(1130):179-81.

Miller WL, Belardinelli L, Bacchus A, Foley DH, Rubio R, Berne RM. Canine myocardial adenosine and lactate production, oxygen consumption, and coronary blood flow during stellate ganglia stimulation. Circ Res, 1979; 45:708-18.

Mobilia G., Zuin G. Zanco P., DiPede F., Pinato G., Neri G., Caranel S., Raviele A., Ferlin G., Buchberger R., Effects of spinal cord stimulation on regional myocardial blood flow in patients with refractory angina. A positron emission tomography study. G Ital Cardiol. 1998 (10):1113-9.

Mosher P, Ross J, McFate PA, Show RF. Control of coronary blood flow by an auto regulatory mechanism. Circ Res 1964;14:250-9.

Murphy DF, Giles KE. Dorsal column stimulation for pain relief from intractable angina pectoris. Pain 1987;28:365-368.

Murray S, Carson KG, Ewings PD, Collins PD, James MA. Spinal cord stimulation significantly decreases the need for acute hospital admission for chest pain in patients with refractory angina pectoris. Heart 1999;82:89-92.

Murray S, Collins PD, James MA. Neurostimulation treatment for angina pectoris. Heart 2000;83:217-220. 
Myerson BA, Bothius J, Terenius L, Wahlstrom A. Endorphine mechanisms in pain relief with intracerebral and dorsal column stimulation, in $3^{\text {rd }}$ Meeting of the European Society of Stereotactic and Functional Neurosurgery. Freiburg, Germany 1977 (Abstract).

Myerson BA, Brodin E. Linderoth B. Possible neurohumoral mechanisms in CNS stimulation for pain suppression. Appl Neurophysiol 1985;48:175-180.

Norsell H, Eliasson T, Mannheimer C, et al. Effects of pacing induced myocardial stress and spinal cord stimulation on whole body and cardiac norepinephrine spillover. Eur Heart J 1997;18:1890-6.

Olgin JE, Takahashi T, Wilson E et.al. Effects of thoracic spinal cord stimulation on cardiac autonomic regulation of the sinus and atrioventricular nodes. I Cariovasc Electrophysiol May 2002;13:4475-481.

Oliveras, J.L., Hosobuchi, Y., Redjemi, F. and Guilbaud, G., Opiate antagonist, naloxone, strongly reduces analgesia by stimulation of raphe nucleus (centralis inferior), Brain Res 1977;120:211-229.

Rasmussen MB, Hole P, Andersen C, Electric Spinal Cord Stimulation in the Treatment of Angina Pectoris: A Cost-Utility Analysis. Neuromodulation 2004; 7: 89-97.

Robertson RM, Bernard Y, Robertson D. Arterial and coronary sinus catecholamines in the course of spontaneous coronary artery spasm. Am Heart J 1983;105:901-6.

Romano M, Auriti A, Cazzin R. et. al. Epidural spinal stimulation in the treatment of refractory angina pectoris. Its clinical efficacy, complications and long-term mortality. An Italian multicenter retrospective study. Ital Heart J Supp 2000 Jan;1(1):97-102.

Sanderson JE, Brooksby P, Waterhouse D, Palmer RBG, Neubauer K. Epidural spinal electrical stimulation for severe angina: a study of its effects on symptoms, exercise tolerance and degree of ischaemia. Eur Heart J 1992;13:628-33

Sanderson JE, Ibrahim B, Waterhouse D, Palmer RB. Spinal electrical stimulation for intractable angina--long-term clinical outcome and safety. Eur Heart J 1994 Jun:15(6):810-4.

Sanderson JE, Tomlinson B, Lau MJW, et al. The effects of transcutaneous nerve stimulation (TENS) on the autonomic nervous system. Clin Auton Res 1995;5:81-84.

Shealy CN, Mortimer JT, Reswick JB. Electrical inhibition of pain by stimulation of the dorsal columns. Anesth Anaig 1967;46:489-91.

Simpson RD, Robertson CS, Goodman JC. Glycine: a potential mediator of electrically induced pain modification. Biomed lett 1993;48:193-207.

Stiller CO, Cui J-G, O'Connor WT, Brodin E, Meyerson BA, Linderroth B. Release of GABA in the dorsal horn and suppression of tactile allodynia by spinal cord stimulation in mononeuropathic rats. Neurosurgery 1996;39:367-375.

Taylor R, Taylor RJ, Van Buyten JP, Buchser E. North R, Bayliss S. The cost effectiveness of spinal cord stimulation in the treatment of pain: a systematic review of the literature. J Pain Symptom Manage 2004;27:370-337.

The Medical Letter. Antibiotic prophylaxis for surgery. Treatment guidelines. 2004;2(20):27-32.

Tonelli L, Setti T, Falasca A et.al, investigation on cerebrospinal fluid opioid and neurotransmitters related to spinal cord stimulation. Appl Neurophysiol 1988;51:324332. 


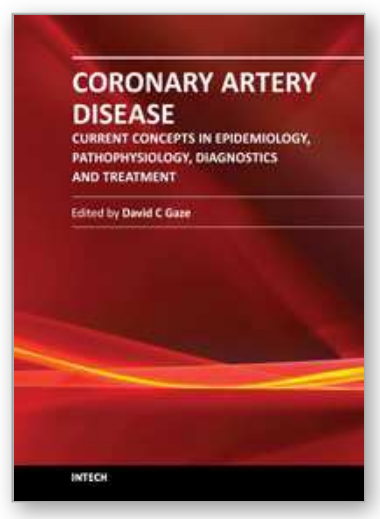

\author{
Coronary Artery Disease - Current Concepts in Epidemiology, \\ Pathophysiology, Diagnostics and Treatment \\ Edited by Dr. David Gaze
}

ISBN 978-953-51-0262-5

Hard cover, 272 pages

Publisher InTech

Published online 16, March, 2012

Published in print edition March, 2012

Cardiovascular disease is ranked as the leading cause of death world wide, responsible for 17.1 million deaths globally each year. Such numbers are often difficult to comprehend. Heart disease kills one person every 34 seconds in the USA alone. Although the leading killer, the incidence of cardiovascular disease has declined in recent years due to a better understanding of the pathology, implementation of lipid lowering therapy new drug regimens including low molecular weight heparin and antiplatelet drugs such as glycoprotein Ilb/llla receptor inhibitors and acute surgical intervention. The disease burden has a great financial impact on global healthcare systems and major economic consequences for world economies. This text aims to deliver the current understanding of coronary artery disease and is split into three main sections: 1 . Epidemiology and pathophysiology of coronary artery disease 2 . Coronary artery disease diagnostics and 3 . Treatment regimens for coronary artery disease

\title{
How to reference
}

In order to correctly reference this scholarly work, feel free to copy and paste the following:

Billy Huh (2012). Spinal Cord Stimulation for Managing Angina from Coronary Artery Disease, Coronary Artery Disease - Current Concepts in Epidemiology, Pathophysiology, Diagnostics and Treatment, Dr. David Gaze (Ed.), ISBN: 978-953-51-0262-5, InTech, Available from: http://www.intechopen.com/books/coronary-arterydisease-current-concepts-in-epidemiology-pathophysiology-diagnostics-and-treatment/spinal-cord-stimulationfor-managing-angina-from-coronary-artery-disease

\section{INTECH}

open science | open minds

\section{InTech Europe}

University Campus STeP Ri

Slavka Krautzeka 83/A

51000 Rijeka, Croatia

Phone: +385 (51) 770447

Fax: +385 (51) 686166

www.intechopen.com

\section{InTech China}

Unit 405, Office Block, Hotel Equatorial Shanghai

No.65, Yan An Road (West), Shanghai, 200040, China

中国上海市延安西路65号上海国际贵都大饭店办公楼 405 单元

Phone: +86-21-62489820

Fax: $+86-21-62489821$ 
(C) 2012 The Author(s). Licensee IntechOpen. This is an open access article distributed under the terms of the Creative Commons Attribution 3.0 License, which permits unrestricted use, distribution, and reproduction in any medium, provided the original work is properly cited. 